\title{
The Urgent Need to Train Teachers for Multigrade Pedagogy in African Schooling Contexts: Lessons from Uganda and Zambia
}

\author{
Charles Kivunja ${ }^{1}$ \\ ${ }^{1}$ Senior Lecturer in Pedagogy and Educational Leadership; Researcher: Embedding Social Media Technologies in \\ Pedagogy; Manager Leximancer Qualitative Software. School of Education, The University of New England, \\ Armidale, New South Wales, Australia \\ Correspondence: Dr. Charles Kivunja, School of Education, The University of New England, Armidale, 2351, NSW, \\ Australia. Tel: 61-412-466-184.E-mail: ckivunja@une.edu.au; c.kivunja@bigpond.com \\ Received: March 28, 2014 \\ doi:10.5430/ijhe.v3n2p63 \\ Accepted: April 13, 2014 \\ Online Published: April 15, 2014 \\ URL: http://dx.doi.org/10.5430/ijhe.v3n2p63
}

\begin{abstract}
Our research project funded by the British Council on multigrade teaching capacity building in Uganda and Zambia found that Uganda does not have a single higher education institution training teachers in multigrade pedagogy and Zambia has only one located at Serenje village in rural Zambia. Yet the research found that in both countries many teachers actually teach multigraded classes in spite of never having been trained in multigrade pedagogy. Our literature searches also found that this situation is not unique to these two countries but in fact very common throughout Africa. Moreover, multigrade is used not by pedagogical choice but by necessity because these countries do not have enough teachers, classrooms or other school equipment to universalize access to primary schooling on a monograde basis. Yet we know that there are well founded pedagogical reasons for using multigrade pedagogy in the education of learners, young and old. These findings lead us to the conclusion that it is not prudent to continue overlooking the potential of multigrade pedagogy to improve educational opportunities for children in African schooling contexts. This is especially true in rural and remote areas; it is therefore imperative to train teachers for multigrade pedagogy in Africa. This paper discusses the problems facing multigrade teaching in Africa and the reasons why multigrade has been neglected, the consequences of that neglect, and the need for a paradigm shift towards multigrade teaching so as to provide universal access to primary education for all children in Africa.
\end{abstract}

Keywords: Monograde pedagogy, Multigrade pedagogy, Multigrade teaching strategies, National primary school curriculum, Paradigm shift, Pre-service teacher trainees, Universalisation of access to primary schooling.

\section{An Understanding of Multigrade Pedagogy}

\subsection{What We Mean by Multigrade Pedagogy}

As there are multiple and even competing understandings of "multigrade", our study begins by looking for definitions. This will ensure that readers have a common understanding of what we mean by 'multigrade' teaching. In an extensive review of literature on multigrade teaching Brown (2008) pointed out that multigrade teaching does not appear to be given a common definition by researchers and educators. Ambiguities arise especially because terms which are not synonymous have been used interchangeably in the literature to refer to multigrade teaching. Terms such as 'multi-age', 'composite groups', 'combination classes' (Mason \& Burns, 1996; Kyne, 2005) 'multilevel', multiskill', 'multipersonality' (Hargreaves, 2001), 'multiple class', 'family class', 'unitary school', (Russell, Rowe, \& Hill, 1998), 'double classes', split classes', 'blended classes', and 'vertically grouped classes' (Katz, 1992; Russell, Rowe \& Hill, 1998; Veenman, 1995), have all been used to describe classes with more than one grade level. So, exactly what is multigrade teaching?

In African contexts (Brown, 2010, p. 7), the preferred definition is offered by Kyne (2005): "multigrade teaching is understood as referring to a case or cases where learners who are supposedly in different grade levels are taught in one class, by one teacher at the same time. This shows that multigrade teaching is embedded in the graded system. Students in multigrade classes retain their grade designation".

Kyne's definition agrees with Pridmore's (2007, p.6), which refers to multigrade as "a situation in which one educator has to teach students of two or more grade levels during one time-tabled period usually in the same classroom". This contrasts with 'multi-age' contexts in which one classroom has learners comprised of age variations 
and differentiations. Such age variations occur even in classes that are traditionally classified as monograde and should not be used as a descriptor of a multigrade class (Kyne, 2005).

As Brown (2010) points out, in many African countries children (and even adults) enter school for the first time, or re-enter school, at vastly different ages. This is evident for example, in schools in Northern Uganda, South Sudan, The Democratic Republic of the Congo and Sierra Leone, and in many other countries in Sub-Saharan Africa, where following displacement by armed conflicts, children and adults re-enter school at different ages. This practice is also common throughout Sub-Saharan African countries in remote areas where only a few schools exist and therefore cater to a wide range of ages. In these contexts, learners of different ages are placed in one class, not because of their age but because of the entry point to the school system and curriculum. As a result, many students in African schools are multi-age but belong to a single curriculum grade, and are therefore in monograde classes. This is why leaders in the field such as Little (1995), Hargreaves (2001), Kyne (2005) and Brown (2010) have argued that many of the labels cited above fail to depict the nature and character of multigrade. The essential feature of multigrade is that the curriculum for the grades in one class is integrated and common elements from the grade-specific curriculum are pooled into one learning program for the learners in one class (Miller, 1991; Pratt, 1986). This explanation makes Professor Angela Little's (1995, p. 4) definition also quite helpful:

Multigrade teaching refers to the teaching of students of different ages, grades,

and abilities in the same group... it is to be distinguished from 'mono-grade'

teaching in which students within the same grade are assumed to be more similar

in terms of age and ability ... it is also to be distinguished from multi-age-within-grade teaching,

which occurs when there are wide variations in age within the same grade.

\section{Incidences and Experiences of Multigrade Pedagogy in the World and in African Countries}

\subsection{Incidences of Multigrade Pedagogy in the World Outside Africa}

Before zeroing in on the extent to which multigrade teaching is practised in Africa, it is helpful to have some understanding of its application in other countries in the world. As a matter of fact, the incidence of multigrade in highly developed countries, including Australia, many European countries including England, Scotland, Ireland, Scandinavian countries and Canada is quite high. For example, Little's (2006, pp. 5-6 and 2007, p.5) data below paint a kaleidoscope of the extent to which multigrade teaching is implemented in some of the welthier countries of the world.

- In Australia in 1988, $40 \%$ of schools in Northern Territory had multigrade classes;

- In France in 2000, 34\% of public schools had combined classes;

- In England in 2000, 25.4\% of all classes in primary education were classified as mixed-year classes;

- In Ireland in $2001,42 \%$ of primary school classes.

Kyne (2005) reported the following data:

- Norway, $42 \%$

- Austria, $25 \%$

- Greece, $31 \%$

- Czech Republic, 35\%

Other sources (indicated in square brackets) give some additional data:

- Switzerland, 23\% [Poglia \& Strittmatter, 1993];

- Sweden, 33.3\% [Malmros \& Sahlin, 1992]

- The Netherlands, 53\% [Commissie Evaluatie Basisonderwijs, 1994];

- Scotland, 26.86\% [Scottish Executive, 2002];

- Canada, 14.2\% [Gayfer, 1991].

- Peru, 78\% [Tovar, 1989]

- $\quad$ Sri Lanka 24\% [Abhayadeva, 1989].

These data help to dispel the misinformed belief that multigrade teaching is a phenomenon in poor countries and not 
practised in high income countries.

\subsection{Incidences of Multigrade in Africa and the Caribbean}

In developing countries, such as Africa and the Caribbean, data are not readily available; however, the few extant sources indicate a high prevalence of multigrade teaching. The literature shows that throughout African countries multigrade teaching is widely used especially in areas where population density is low, locations are in geographically challenging areas such as mountainous country, semi-arid or desolate, or inaccessible due to poor road networks. This includes islands such as Ssese and Buvuma Islands in Lake Victoria of Uganda, that we surveyed in our study, which is subsequently reported in this paper. Numerous examples can be cited in Zambia, Uganda, Ghana, Mauritania, Lesotho, Botswana, Niger, Nigeria, Senegal, Guinea and Zaire (Thomas \& Shaw, 1992). For example, in South Africa, Brown (2010) found that $37.15 \%$ of all schools were in rural areas and multigrade pedagogy was in practice. The Commonwealth Secretariat data reported by Berry $(2014$, p. 2), also indicate that the use of multigrade teaching is up to $51 \%$ in Belize, $47 \%$ in Guyana; $43 \%$ in Jamaica; $38 \%$ in Dominica; $30 \%$ in Turks and Caicos Islands and 12\% in Trinidad and Tobago. Little (2007, p. 5) reported that in Burkina Faso in 2000, 36\% of schools and $20 \%$ of classes were multigrade; in Mauritania in 2002/2003, 39\% of all pupils were educated in a multigrade class.

\section{The Urgent Need to Train Teachers for Multigrade Pedagogy in Africa; Based on Experiences of Multigrade Teaching and Teacher Training for Multigrade Teaching in Uganda and Zambia}

The latest school census data available for Zambia (2012) showed that $32 \%$ of all primary schools had multigrade classes. The Ugandan data were inconclusive because the census does not have a category identified as 'multigrde schools', but estimates from officials we interviewed indicated a magnitudes of about $28 \%$. The lower proportion of schools with multigrade classes in Uganda compared to Zambia is understandable because Zambian rural areas are much more sparsely populated than Uganda's rural areas. Also, nationally, Uganda's population of 36.35 million is more than double that of Zambia's 14.8 million, (World Bank, 2014). The multigrade primary schools we visited in Uganda and Zambia varied in size from 50-80 pupils in the small ones to 400-500 in the large ones. Both these countries run a seven grades primary schooling system. This means that in the small schools, a grade could contain only $7-11$ children, who were too few to have a teacher of their own; or in the large schools each grade was 57-71 children. Each of these contexts created multigrading problems. The small schools had to combine several grades into a viable class size to be taught by one teacher (three grades into one class of about 30 pupils) and the large schools had to combine grades because they did not have enough teachers to provide one for each grade (one class with two grades of over 100 children).

We know from our literature searches (Kivunja \& Wood, 2012) that these large variations in class sizes in Uganda and Zambia are quite common in other African schools. For example, CREATE (2008) reported that in Ghana the smallest school had 24 students and the largest 1,500. In South Africa the figures were 68 and 2,017 respectively; in Uganda $4 \%$ of all schools had less than 100 pupils, but 64\% in Mauritania. In Benin, Ghana, Burkina-Faso and Niger, $5 \%$ of all schools had more than 500 students each. Although studies on how school size impacts on student achievement are inconclusive regarding optimal class size, studies such as Schutz (2006) provide reasonable evidence that school size matters. We also know from Little's (1995) study of multigrade teaching in two schools in Zambia, - Mwape and Kalombe -, that class size influences the decision to run the class as monograde or multigrade. In Mwape, the class sizes were very small and so the school was run with multigrade classes. In contrast, the class sizes in Kalombe had grown significantly from 123 pupils in 1985 to 204 in 1988 and so the increased enrolments justified a switch from multigrade teaching to monograde teaching.

We found that in both Uganda and Zambia, the teachers had not been trained for multigrade teaching. In both countries it is assumed that a monograde organization of schooling is the expected norm. Our literature search confirmed that such lack of training for multigrade teachers appears to be a problem experienced widely across Africa, rendering the situation in Uganda and Zambia as the norm. For example, in South Africa Titus (2004, p. 10) found that many teachers in multigrade contexts were "either untrained or only trained in single-grade pedagogy". Even in Zambia where multigrade teaching had been formally introduced in a number of schools some thirty years ago (Lungwanga, 1989), we found that there was no curriculum developed for multigrade teaching. Moreover, in our interview with the District Education Officer, we found that while there was an understanding that multigrade pedagogy was needed to help universalize access to primary education, there was also the perception that not training teachers for multigrade teaching was not an issue. It appeared as though those that recognized that not having teachers specially trained to teach multigrade classes was a problem, saw no immediate solution and therefore put it off their agendas and financial budgets in planning the education in their districts. This also explains why the only 
curriculum available for multigrade teachers to work with is the national primary school curriculum, designed for monograde teaching. This lack of congruence between policy and implementation of multigrade is not unique to Uganda or Zambia as we found in our analyses of multigrade policies and practices in Bhutan (Kivunja et al. 2012; Kivunja et al. 2013).

This problem was more serious in Uganda than in Zambia. This is because Zambia has a multigrade Teacher Training College (TTC): - Malcolm Moffat Teachers' Training College, at Serenje. However, Uganda does not have any TTC dedicated to training teachers in multigrade pedagogy. At Serenje, the dedicated multigrade TTC conducts in-service training courses in multigrade teaching for practising teachers and also provides training of pre-service teachers for multigrade pedagogy. However, interview data some of which are presented below, showed that because multigrade teaching is not given formal status in schools and no special curriculum was provided by the Ministry of Education, students did not take it seriously. Unlike other subjects, multigrade teaching is not examined and so education students don't treat it with the same degree of enthusiasm or interest as the other subjects that they need to complete for the award of their Teachers Certificate. Multigrade was therefore seen as some kind of fill-in subject, to be done when the more important subjects had been completed.

Attitudes about multigrade that we found among the 28 teacher trainees we interviewed were mixed. Over $70 \%$ of them (20 of the 28), made comments that indicated that they valued their training in multigrade pedagogy. For example, in answer to the question: 'What is your view about your being trained for multigrade teaching'?, a positive orientation was well articulated by one student:

"I think it is very good because I know that when I graduate here, I will be able to teach

in both types of schools, monograde and multigrade".

But among nearly $30 \%$ ( 8 of the 28 ) of the interviewees who were not positive towards multigrade, in answer to the same question one student said:

"It's kind of a waste of our time, because no one wants to do it. Because you know if you do it,

you are going to teach in the bad schools, schools where no one wants to go or to stay,

and schools where the children are very difficult. They don't want to learn".

Another negative response said:

"Who wants to teach in the most remote areas; I mean, there is nothing there.

All your friends are in the city and you rot in the remote villages of the country?

And the schools have nothing in them; you have to improvise so much, every day".

Yet another student voiced an unfavorable concern saying:

"We should be paid double the normal salary of a teacher in a monograde class

because we are doing twice as much work as they do". And we are denied all privileges

available in the town schools".

These findings corroborated with earlier findings by Titus (2004) who found that teachers in South African rural schools where multigrade was common had a low opinion of multigrade and regarded "the multigrade classroom as a poor relation to the better resourced, single-grade classrooms" (p. 10).

During our research, the Malcolm Moffat College ran multigrade teaching demonstration lessons that were attended by the pre-service teacher trainees as well as five teachers from two of the neighboring local schools that have multigrade classes. In the schools we visited where the multigrade classes were being taught by teachers without formal training in multigrade pedagogy, there was ignorance of the principles and strategies for the implementation of multigrade pedagogy as well as anxiety about what multigrade teaching involves. Yet, because of the acute shortage of teachers, it was not possible for the untrained teachers to take a day off to go and attend in-service workshops organized by Malcolm Moffat TTC.

Although the teachers in the Zambian multigrade schools we visited had not been trained at Malcolm Moffat TTC, the principals and teachers we interviewed expressed hope that in the future graduates from Malcolm Moffat TTC would be posted to their rural multigrade schools. For Uganda, however, there was no prospect for the supply of teachers trained in multigrade pedagogy as none of the TTCs in the country, train teachers for multigrade teaching. Indeed the training sessions we conducted for 28 teachers were their first experience with multigrade pedagogy. 
Our literature search revealed that a very big problem that both Uganda and Zambia face is that of the rapid population growth rate. This is particularly so for Uganda where Carl Hub (2014) a demographics expert at the World Population Reference Bureau in Washington estimates its current population of 36.35 million people to grow at a natural rate of $3.4 \%$ per annum and reach 130 million in 2050. This estimate puts Uganda "On track to have the world's highest population growth rate" (Ibid) when compared to the world's average of $1.5 \%$ per annum. Although Zambia is starting from a lower base of nearly 15 million, (14.8 million), its annual growth rate is also very high at $3.2 \%$ per annum, (Ibid). This, with an embedded fertility rate of 6.28 children per woman (Ibid), means that Zambia, like Uganda, is also facing a projected population explosion.

Although Uganda's population growth rate is regarded as exceptionally high, most African countries also have high growth rates. For example, according to the Population Reference Bureau, (2013), fertility rates in Sub-Saharan Africa are among the highest in the world, and the population in sub-Saharan Africa, is expected to grow from the current 926 million people to nearly 2.2 billion by 2050: the largest growth of any region in the world. This population explosion calls for foresight and planning so that Africa will be able to educate its youths. It is highly unlikely that Africa will have the resources to provide the human expertise and physical resources needed to universalize access to primary education for all its projected children. This challenge is likely to be better addressed by applying the strategies of multigrade pedagogy than those of the current practice of monograde teaching.

\section{The Benefits That Could Accrue From Implementation of Multigrade Pedagogy in African Primary Schools}

We know from experiences in multigrade schools in the Turks and Caicos Islands, (Little, 2006, p.33) that some children in multigrade schools performed better in reading than those in monograde classes. In addition, Juvane (2007) states that multigrade teaching can improve the quality of teaching. Likewise, Berry (2010) contends that multigrade teaching can be a particularly efficient and effective way to provide education especially where small schools exist due to low population density in the area. CREATE (2008) reported that multigrade teaching in small rural schools had the following advantages:

- Because they are located within easy reach of local communities they can more easily respond to local needs and conditions better than larger schools sited outside communities.

- Children do not have to travel long distances because the schools are sited locally.

- Small schools encourage the development of identity, which makes it it easier to plan for individual students' learning.

- Teachers know their pupils more and they can more easily design more holistic approaches for the children's individual development.

In Latin American countries (Tovar, 1989), multigrading can increase universalisation of access to primary education especially in the poor countries for several reasons:

1. By aggregating children of different grades together, multigrade education can draw on economies of scale whereby one teacher teaches these grades. This helps to alleviate the problem of teacher shortage.

2. Because multigrade classes can be much smaller than monograde classes, (provided they are not too small to be uneconomical) particularly in the rural areas, they can be established more cheaply.

3. Their low cost structure means that more of them can be established thereby taking education to the people in rural areas where it is needed the most. This is important because many of the remote areas have poor roads and difficult terrain that makes travel very difficult.

4. The combination of grades might mean that younger children attend the same class with their older siblings. This gives them support and makes schooling a less threatening experience especially in the earlier primary school years.

5. Because they can be easily set up in the rural areas, children do not have to travel long distances to go to school. This can be a significant advantage not only for the security of the children but because it gives the children more time outside school so that if needed, as is often the case, they can contribute to income generating activities for their families, e.g. helping to pick crops, herd livestock, gather firewood or fetch water.

6. Related to the above reason is that more children from each family can attend school thereby increasing school enrolment.

7. Smaller classes have the advantage that the teacher can pay more attention to the children that need it. 
8. Ensuring schools operate in local communities increases the likelihood of community support for the schools and possible parental involvement in the schools' activities.

\section{Problems Facing Multigrade and Reasons Why Multigrade Pedagogy Has Been Neglected}

In spite of the potential benefits of multigrade outlined above, multigrade teaching faces many problems, not because it is multigrade pedagogy, but because of the contexts and surroundings in which multigrade teaching takes place. These problems have contributed significantly to its neglect in African schooling contexts. The most fundamental of these contextual problems for the implementation of multigrade pedagogy in Africa appears to be the absence of official government policy advocating and supporting the implementation of multigrade pedagogy. We found this to be a significant problem in both Uganda and Zambia, leading parents and teachers to regard multigrade teaching as the teaching children have if they can't have 'normal teaching' in a monograde classroom. This contrasts sharply with experiences in other countries where multigrade pedagogy enjoys official government support as in Colombia (Colbert, Chiappa \& Arboleda, 1993) and Sri Lanka (Ratnaike, 1987), and enjoys relatively greater success.

Another contextual problem is that many multigrade schools cannot recruit enough teachers because they are in remote areas. In Uganda, for example, we were told that these areas and schools are colloquially referred to as 'hardto-reach-hard-to-stay-hard-to-staff' locations. This trifecta of problems is a major stumbling block in any implementation of effective multigrade pedagogy. We found in Uganda and Zambia that the teachers appointed to these schools stayed for only a short period of time because the areas had little opportunity for professional development and social networking.

We also found among the very small multigrade schools (with less than 25 pupils) on Ssese Island in Uganda that they had much higher costs of operation for several reasons. Firstly, they do not have economies of scale because of the low student enrolment. Secondly, their location on the island made transport difficult and expensive, often involving canoes, then motor bikes (locally popularly known as 'Boda-boda', which are prone to accidents) or simply walking for long distances. High cost structures are quite common wherever small multigrade schools are found as reported for instance by Blum and Diwan (2007) in India.

In Zambia another problem we noted was that most of the multigrade schools were located in rural areas that are geographically isolated from the major townships in Serenje and Lusaka. As a result, access to these schools is difficult, population is sparse and the living conditions are rather harsh and unwelcoming to teachers. In both countries (Uganda and Zambia) parents who could send their children to non multigrade schools in the urban areas did, leaving mainly socially marginalized groups who could hardly afford to pay the expenses needed for their school equipment, such as exercise books and textbooks, to keep their schools running. A fourth problem we discovered in both these countries was that the sparsely populated rural communities were too poor to contribute to the physical infrastructure of their local school, let alone contribute to the recruitment of trained teachers for their schools. As a result most of the teachers we found teaching in these multigrade schools were graduates of year 12 high schools who had had failed to gain entrance into university or college education. In other words, they had failed their Higher School Certificate Examinations. In a couple of the schools we visited the teachers were actually School Certificate holders (year 10 graduates) rather than Higher School Certificate graduates (year 12).

In both countries, there were signs of poverty, malnutrition and children spending the day at school without a proper meal for lunch. Considering that many of them would have left home without a decent breakfast, it is easy to understand why it would be difficult for such children to be attentive in class and to engage actively in meaningful learning. Another problem we found was that most of the multigrade schools were poorly equipped and teachers had little or no access to teaching materials and learning resources such as blackboards, chalk, dusters, tables, desks and chairs.

Because teachers conducting multigrade classes had not been trained in the specific skills required for multigrade teaching, their teaching methodologies tend to rely on passive strategies which do not create opportunities for students to be actively engaged in their learning in the Vygotskian (1978) constructivist paradigm. The problem of lack of training of teachers for multigrade teaching is exacerbated by the absence of a curriculum developed to support the teaching of multigrade classes. Instead, teachers in multigrade contexts have to rely on the same curriculum that is developed for monograde teaching.

Not only do multigrade schools face the problem of not having teachers purposely trained for multigrade, but they also face the problem of having the least qualified teachers sent to them. For example, of the 23 teachers interviewed in rural multigrade schools in Zambia, 20 of them had no formal teaching qualification. In Uganda the untrained teachers had been hired locally by parents who were responsible for the establishment of the multigrade 
schools in their areas and while the teachers had completed primary schooling, they had not successfully completed the School Certificate exam sat at the end of year ten, middle school, to advance their studies to high school. To make a bad situation worse, these teachers taught classes with two combined grades (grades 1 and 2; and 3 and 4) totaling 65 children in each class and three combined grades (grades 5,6 and 7) with a total of 78 pupils in each class. Even with very good teacher training, such large class sizes would pose an enormous challenge to the teacher.

The combination of two or three grades as we found in Uganda and Zambia, highlights a problem that all multigrade contexts face, and that is the wide range of abilities and interest levels in one class. Of course, even in a monograde class of 30 pupils, there is a wide range of abilities among the children. However, the range of abilities is amplified many more times when you have, not 30 but 65 or 78 pupils in one class.

The children in grade 7 in both Uganda and Zambia are required to sit a series of external summative assessment tests or exams for what is called the Primary Leaving School Certificate (PLSC). Yet in Uganda, grade 7 students were in combined classes with grade 5 and 6 . Preparing students for any public summative assessment tests or exams is always difficult but preparing grade 7 for the PLSC in the same class with grade 5 and 6 who do not have to sit an examination makes it considerably more challenging for the teachers. They have to balance their instructional time between focusing on the critical PLSC content and that for the other grades for whom time is not so crucial.

Another problem that multigrade schools face is that because they are located in rural, poor areas, the parents are far too busy earning a living resulting in their not having time or money to support the developments required at their local schools. This is sometimes misinterpreted as lack of interest in their children's education or indifference. However, the real problem seems to be the difficulty of parents being involved in their children's schools programs.

\section{What Is Needed to Make Multigrade Pedagogy a Success in African Contexts?}

\subsection{Political Insights and Planning}

Aware that a multigrade class is not just another class but one with special characteristics which call for specialist training, African governments should acknowledge these differences and develop legislation and policies which categorically advocate multigrade pedagogy along with the necessary funding to train new teachers for multigrade teaching and to provide in-service teacher training. These policies could provide for a special department within the Ministry of Education to be assigned the mandate for the development of a national curriculum for the teaching of multigrade pedagogy in the country. In addition to supporting legislative and political infrastructure, governments should make the development of multigrade pedagogy and teaching a high priority and provide necessary buildings, classroom equipment and teaching materials to facilitate the teaching of multigrade pedagogy particularly in rural and remote areas. Understaffing in multigrade schools was a problem that was rampart in both Uganda and Zambia. Every effort should be made by the respective departments to provide enough teachers and in areas where teachers move from rural schools, arrangements should be made to support the remaining teachers with the supply of casual and temporary teachers. That support should also be given in instances where teachers fail to report for duty. As the countries do not have enough resources to provide trained teachers for education based on monograde teaching, emphasis should be placed more on the training of teachers for multigrade pedagogy rather than the opposite. Moreover, a teacher that is well trained in multigrade pedagogy can teach a monograde class very well whereas the reverse is not the case.

\subsection{Training of Pre-service Teachers}

Teacher Training in universities and colleges should include within the teaching methodologies courses, specific units, that train pre-service teachers in the strategies needed for he implementation of efficient and effective multigrade pedagogy. As evidenced in the quotes from teacher trainees we interviewed, there are some negative perceptions and attitudes among teacher trainees towards multigrade pedagogy. These negative perceptions and attitudes need to be rectified by the training given to pre-service teachers in their multigrade pedagogy unit.

\subsection{Special consideration for multigrade teachers}

Even with adequate training, the preparation and teaching of multigrade, with classes comprising two or three and sometimes more grades, places a lot of demand on the teacher's planning and instructional time. Handling such a wide range of students' abilities is very challenging, especially when in some instances, the numbers are extraordinarily large. In view of this problem, consideration should be given to offering them an incentive. This could be, for example, in the form of a financial incentive, leave allowance, the provision of accommodation, employment of spouses, and creating opportunities for promotion in the rural areas which tend to miss out. Teachers in multigrade contexts need to feel that they are supported in managing the many challenges that multigrade teaching requires. 


\subsection{In-service Training of Practicing Teachers}

Since practically all teachers serving in most jurisdictions in African primary schools did not receive specialist training on multigrade pedagogy, it is essential that they be provided with on-going in-service training for multigrade teaching. Different strategies could be employed to make such in-service professional development efficient and effective. The model we used both in Lusaka (Zambia) and Kampala (Uganda) involved bringing teachers from the rural areas to the TTCs in Lusaka and Kampala, respectively, where we conducted the training workshops for teaching multigrade. An alternative that Malcolm Moffat College at Serenje in Zambia used and was quite effective and economical, was to invite teachers from neighboring multigrade classes to the TTC to observe demonstration lessons in multigrade teaching. The teaching was done by one of the few teachers trained in multigrade pedagogy and it was watched by both pre-service a as well as the visiting in-service teachers from the nearby schools. This benefited both the teacher trainees and the local teachers.

\subsection{Education of Parents}

From parents' perceptions of multigrade as the teaching their children got because they couldn't get the traditional monograde teaching in both Uganda and Zambia, we see a need for the public education of parents so they appreciate the necessity and merits of multigrade pedagogy and eliminate this conceptual bias. Public statements at ministerial level and down to Provincial and District Education Officers in support of multigrade pedagogy are needed to inform and to convince parents of the merits of multigrade pedagogy. For example, some parents both in Uganda and Zambia wondered how their children of different grades could possibly be taught in one class by one teacher at the same time. Some felt that the older children were disadvantaged while the younger ones were overwhelmed.

We also found in the Serenje District, that in some instances, when enrolments had increased, schools stopped multigrade teaching and reverted to monograde. This practice tends to reinforce the perception among parents that monograde is always the preferred option and to see multigrade as a temporary situation which will be dropped when enrolments improve. Parents should know that multigrade schools will always remain multigrade schools and will be funded and resourced accordingly.

\section{Conclusion}

Based on our research in Uganda and Zambia, and on the literature on human and other resources availability in African countries, it is our view that it is unrealistic to expect these countries to be able to universalize access to primary education without a paradigm shift from the monograde model of teaching to multigrade pedagogy. The data show that Africa's population is growing very rapidly and the demand for access to primary education is only going to intensify with time. The evidence strongly suggests that for millions of children in Africa, as witnessed in Uganda and Zambia, the only way they will be able to access schooling will be through multigrade schools, in which one teacher will be responsible for children of more than one curriculum grade at the same time. Multigrade pedagogy, if staffed with adequately trained teachers, and in schools that are well resourced with teaching materials and nourished children, offers a unique promise to bring education to the children who need it the most, which is true for most of Africa, particularly in the rural and remote areas. A starting point for success is the training of teachers, purposely skilled in how to teach multigrade classes, so that they can deliver quality education. The present model of teacher training for monograde teaching, turns a blind eye to the realities of schooling in most African rural schools, and is incognizant of the magnitude of the problem and the urgent need for a paradigm shift from monograde to multigrade teaching.

This paradigm shift is long overdue since these countries were supposed to achieve universal access to primary schooling as a millennium development goal by 2015. This shift calls for a political vision and willingness to initiate the necessary change and to provide the training and other resources to make multigrade teaching the solution for African children of primary school age. We found a widely held perception among some of the parents we interviewed in Uganda and Zambia, that multigrade teaching was regarded as the schooling children were given because monograde was not available in their area. It was therefore denigrated which explained why the parents who could afford it, sent their children to schools long distances away from their homes. For Ssese Island in Uganda, for example, this meant sending the children off the island to mainland schools in Masaka and Kyagwe Districts at considerable expense. For this reason we recommend that the governments in African countries educate parents about the virtues of multigrade pedagogy, backed with government support to resource the schools adequately.

We know from experiences in Siri Lanka, Colombia and Peru (Tovar, 1989) that an increase in the number of one-and two-teacher schools (therefore multigrade schools) resulted in a significant increase in the provision of 
primary schooling. We also know from experiences in Colombia's New School Program, (locally known as Escuela Nova), that when multigrade schooling was organized to allow for flexible progression across grades and for curricula designed to reflect rural contexts, enhanced with instructional materials that supported self-study and individualized learning, children in grades 3 and 5 in the multigrade classes performed significantly better than children in similar grades in traditional rural schools that were monograde schools (Colbert, Chiappa \& Arboleda, 1993). We also know from studies based on evidence from North America (Pratt, 1986), that when children's cognitive outcomes are compared, children in multigrade classes perform no better and no worse than those in monograde classes. Our research in Uganda and Zambia (Kivunja \& Wood, 2012) found that children in the multigrade classes had achieved better grades than those in monograde classes. Similarly, Mycock (1970) and Ford (1977) in their studies in England found that while there were no differences in vocabulary growth, reading accuracy, and mathematical skills among infants in monograde and multigrade contexts, there were greater achievements in a range of socio-emotional factors, including friendships, self-esteem, social development, self-concept, attitudes towards school and civic behavior for the children in multigrade contexts. Thus, based on a large body of evidence, from Uganda, Zambia and elsewhere in the world, we strongly suggest that it would be imprudent for African countries to continue ignoring the potential of multigrade pedagogy to accelerate universalisation of access to primary education for the rapidly growing population of school children.

\section{References}

Berry, C. (2010). Multi-grade Teaching. Discussion Document. Retirieved on 18 December 2013 from http://www.ioe.ac.uk

Berry, C. (2014). Multigrade teaching: A discussion Document. Institute of Education, University of London. Accessed online at http://www.ioe.ac.uk/multigrade on 6 March 2014.

Blum, N. \& Diwan, R. (2007). Small, multigrade schools and increasing access to primary education in India: National Context and NGO Initiatives, CREATE: Pathways to Access; Research Monograph No. 17.

Brown, B. A. (2008). Multigrade teaching: A review of selected literature and implication for educator education and training in South Africa. East London: University of Fort Hare.

Brown, B. A. (2010). Multigrade teaching: A review of issues, trends and practices; Implications for teacher education in South Africa. Johannesburg: Centre for Education Policy Development.

Colbert, V., Chiappa, C. \& Arboleda, J. (1993). The New School Program: More and better primary education for children in rural areas in Colombia. In H. M. Levin \& M. E. Lockheed. Effective schools in developing countries, London: Falmer Press.

CREATE (2008). Size matters for EFA: Policy brief. Cress, Consortium for Research on Educational Access, Transistions and Equity, Accessed Online at: http://www.create-rpc.org on 26 March 2014.

Ford, B. E. (1977). Multiage grouping in the elementary school and children's affective development: A review of recent research. The Elementary Journal, Nov. 1977, pp. 149-159. http://dx.doi.org/10.1086/461096

Hargreaves, E. (2001) Assessment for learning in the multigrade classroom. International Journal of Educational Development, 21(6), 553-560. http://dx.doi.org/10.1016/S0738-0593(01)00015-3

Hub, C. (2014). Uganda on track to have the world's highest population growth, Population Reference Bureau, Washington, DC. Accessed on 28 March 2014 at: http://www.worldwatch.org/node/4525

Juvane, V. (2007). Multi-grade teaching can improve quality of primatry education. Commonwealth Education. Retieved on 18 March 2014 from http://www.thecommonwealth.org/news/160291/090307teaching.htm

Katz, L. (1992). Non-graded and mixed-age grouping in early childhood programmes. Urbana, IL: Eric Clearinghouse in Early Childhood Education.

Kivunja, C., Kucita, P., Kuyini, A. B. \& Maxwell, T. (2012). Factors influencing Bhutanese teachers' multigrde knowledge and teaching practices. Bhutan Journal of Research and Development, 1(2), 109-123.

Kivunja, C. \& Wood, D. (2012). Multigrade pedagogy and practice: Accelerating millennium development goals for Sub-Saharan Africa, International Journal of Learning, 18(11), 17 - 32.

Kivunja, C., Kucita, P., Maxwell, T. \& Kuyini, A. B. (2013). Bhutanese Stakeholdres' perceptions about multigrade teaching as a strategy for achieving quality universal primary education. International Journal of Educational Development, 33(2), 206-212. http://dx.doi.org/10.1016/j.ijedudev.2012.05.009 
Kyne, C. (2005). The grouping practices of teachers in small two-teacher primary schools in the Republic of Ireland. Journal of Research in Rural Education, 20(17), 1-20.

Little, A. (1995). Multi-grade teaching: evidence from practice and research. London: ODA.

Little, A. (2006). All together now. Multigradue education: several grades, one room. IOE Life, Winter(4), 32 - 33.

Little, A. (ed.) (2007) Education for all and multigrade teaching: Challenges and opportunities, Dordrecht, Springer.

Lungwangwa, G. (1989). Multigrade schools in Zambian primary education: A report on the pilot schools in Mkushi District. SIDA Educational Division Documents, (Vol. 47). Stockholm: SIDA.

Mason, D., \& Burns, R. (1997). Reassessing the effects of combination classes. Educational Research and Evaluation, 89(1), 36 - 45.

Miller, B. (1991). A review of the qualitative research on multi-gradue instruction. Research in Rural Education, 7(2), 3-12.

Mycock, M. A. (1967). A Comparison of vertical groupings and horizontal groupings in the infant school. British Journal of Educational Psychology, 37, pp. 133 - 135. http://dx.doi.org/10.1111/j.2044-8279.1967.tb01917.x

Population Reference Bureau, (2013). Africa to record largest population growth over next 40 years. Accessed from the Internet at: http://www.voanews.com/content/africa-to-record-largest-population-growth-over-next-40-years/1748380.html on 27 March 2014.

Pratt, D. (1986). On the merits of multiage classrooms. Research in Rural Education, 3(3): 111-115.

Pridmore, P. (2007). Adapting the primary school curriculum for multi-grade classes in developing countries: A five-step plan and agenda for change. London: Institute of Education, University of London.

Ratnaike, J. (1987). Report on the Mission to Sri Lanka. UNICEF: Assisted Education Projects, Bangkok. Comparative Education Review, 37(3), 263-276.

Russell, V.J., Rowe, K.J., \& Hill, P.W. (1998). Effects of multigrade classes on student progress in literacy and numeracy: Quantitative evidence and perceptions of teachers and school leaders. Paper presented at the Annual Meeting of the Australian Association for Research in Education (AARE). Nov. - Dec. Adelaide.

Schutz, G. (2006). School size and student achievement in TIMSS 2003. In Loveless, T. (ed). Lessons learned: What international assessments tell us about mathematics achievement. Washington, DC: Brookings Institution Press.

Thomas, C. \& Shaw, C. (1992). Issues in the development of multigrade schools. Washington DC: World Bank Technical Paper 172.

Titus, D. (2004). The Implimentation of Multigrade Teaching in Rural Schools in the Keetmanshoop Education Region: Leadership and Management Challenges. Unpublished PhD Thesis, Grahams Town: Rhodes University.

Tovar, T. (1989). Ser Maestro: Condiciones del Trabajo Docente en el Peru Lima, DESCO/UNESCO.

Veenman, S. (1995). Cognitive and noncognitive effects of multigrade and multiage classes: A best-evidence synthesis. Review of Educational Research, 65(4), 319-381. http://dx.doi.org/10.3102/00346543065004319

Vygotsky, L. S. (1978). Mind in society: The development of higher psychological processes. Cambridge, MA., Harvard University Press,

World Bank. (2014). World development indicators - 2014. Washington, DC: World Bank. 